\title{
Argon as a Tracer of Cross-Isopycnal Mixing in the Thermocline
}

\author{
Cara C. Henning \\ University of California, Berkeley, Berkeley, California \\ DAVID ARCHER \\ University of Chicago, Chicago, Illinois \\ INEZ FUNG \\ University of California, Berkeley, Berkeley, California
}

(Manuscript received 18 May 2005, in final form 6 April 2006)

\begin{abstract}
Noble gases such as argon are unaffected by chemical reactions in the ocean interior, but a number of physical mechanisms can lead to measurable sea level atmospheric disequilibrium in subsurface waters of the ocean. One such mechanism is the mixing of waters of different temperatures, which can lead to supersaturation in the ocean interior. The authors simulate the supersaturation mixing signature in the thermocline in a global ocean general circulation model, Parallel Ocean Program model, version 1.4 (POP 1.4). In contrast to existing mixing diagnostics such as dye tracers or microstructure measurements, which yield the local, recent rate of diabatic mixing, argon disequilibrium traces an integrated lifetime history of subsurface mixing. A theoretical model of the subtropical Atlantic Ocean gyre is built, based on the competing time scales of horizontal and vertical mixing, that agrees well with the full general circulation model argon supersaturation gradient in the thermocline. These results suggest that gyre-scale argon data from the real ocean could be similarly interpreted. The variation of the argon supersaturation with diffusivity in the equatorial Pacific Ocean is also investigated.
\end{abstract}

\section{Introduction}

Fluid flow in the upper thermocline occurs largely along isopycnal surfaces, while the rate of crossisopycnal mixing tends to be small. However, understanding the structure of the thermocline (e.g., Samelson and Vallis 1997), the overturning circulation (Scott and Marotzke 2002), the efficiency of potential carbon sequestration experiments (Mignone et al. 2004), and the degree of high-latitude control on the atmospheric $p \mathrm{CO}_{2}$ concentration (Archer et al. 2000) all require accurate knowledge of the low-latitude thermocline crossisopycnal mixing magnitude. In addition, accurate simulation of biogeochemical tracers along isopycnals depends upon simultaneously constraining the cross-

Corresponding author address: David Archer, Dept. of Geosciences, University of Chicago, 5734 Ellis Ave., Chicago, IL 60637.

E-mail: d-archer@uchicago.edu isopycnal and along-isopycnal diffusivities (Gnanadesikan et al. 2002, 2004).

Existing methods for measuring or inferring the rate of diapycnal mixing are most useful for determining local mixing rates in a sparse number of locations. These methods include observations of the vertical spread of tracers, both in purposeful tracer release experiments (e.g., Ledwell et al. 1998) and in studies using profiles of transient tracers like tritium (Kelley and Van Scoy 1999), and observations of temperature or velocity microstructure measurements (e.g., Ruddick et al. 1997; Polzin et al. 1997). In the few available studies done in the interior ocean away from topography (Ledwell and Watson 1991; Ruddick et al. 1997; Ledwell et al. 1998; Kelley and Van Scoy 1999), there is a consensus that the local cross-isopycnal diffusivity is on the order of 1-3 $\left(\times 10^{-5} \mathrm{~m}^{2} \mathrm{~s}^{-1}\right)$. However, in regions over rough topography, the diffusivity can be enhanced by a factor of 2 or more, even in the upper $1000 \mathrm{~m}$ of the ocean (see Polzin et al. 1997, their Fig. 2). Mixing is also enhanced 
by several orders of magnitude near side boundaries, and regions several hundred kilometers away from side boundaries can have diffusivities enhanced by a factor of 10 relative to more interior values (Watson and Ledwell 2000). Munk and Wunsch (1998) argued that, because of fast communication along isopycnal surfaces, the overall stratification of the ocean ought to depend on the mean rate of mixing rather than on local conditions. There is something of a mismatch between the local scale of the mixing observations and the ocean basin scale over which mixing affects the thermocline structure and meridional circulation.

The distributions of noble gas concentrations in the ocean interior have the potential to act as a tracer for diathermal mixing that will complement tracer and microstructure techniques by giving a basin-scale estimate of diffusivity. These gases are inert to chemical reactions in the ocean, so to a first approximation the concentrations of the gases in the subsurface ocean reflect an equilibrium with the atmosphere when the parcel last left the sea surface. However, several physical processes exist at the sea surface and below that can lead to measurable disequilibrium in the noble gas concentrations. One class of processes involves injection of bubbles into the ocean interior by waves and sea foam or by melting glacial ice. Bubble injection tends to have the strongest impact on gases that are not very soluble, such as neon (Well and Roether 2003). The second class of mechanisms relies on the temperature dependence of gas solubility, since heating or cooling will affect the departure from saturation, and we focus here on the effects of diathermal mixing. Argon is more soluble than neon, its solubility depends more strongly on temperature, and some oceanographic data exist (Hamme and Emerson 2002), so it is a noble gas well suited to isolate and trace diathermal mixing.

Figure 1a shows the argon saturation curve as a function of temperature (solid) at a constant salinity of 35 psu. The dashed line represents a mixing line between two end members at equilibrium at $3^{\circ}$ and $25^{\circ} \mathrm{C}$ (e.g., the abyss and the mixed layer). The argon saturation concentration is a nonlinear function of temperature, so the mixing line lies above the saturation line, indicating that simple mixing leads to supersaturation. Figure $1 b$ translates this difference into supersaturation percent as a function of local potential temperature. The resulting supersaturation is on the order of percent and is a symmetric bump with maximum supersaturation at the midpoint temperature between the end members. In contrast, the dotted lines in Figs. 1a and $1 \mathrm{~b}$ show a mixing line and supersaturation curve if the mixing occurs between $3^{\circ}$ and $16^{\circ} \mathrm{C}$ (e.g., the abyss and the base of the ventilated thermocline). The difference in the
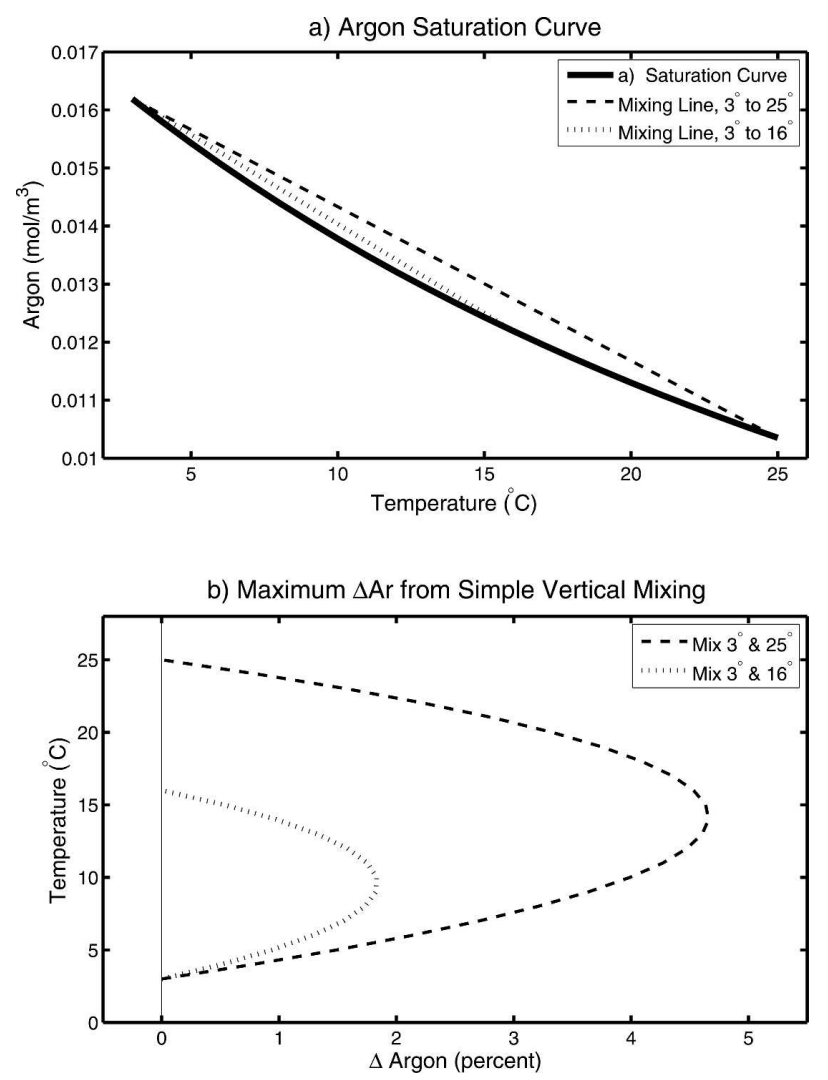

FIG. 1. (a) The argon saturation curve as a function of temperature (solid). The dashed and dotted lines show the argon as a function of temperature if equal volumes of water at saturation are mixed, with the dashed line representing mixing $3^{\circ}$ and $25^{\circ} \mathrm{C}$ water and the dotted line representing mixing $3^{\circ}$ and $16^{\circ} \mathrm{C}$ water. The supersaturation is the space between the mixing lines and the saturation curve. (b) The theoretical $\Delta \mathrm{Ar}$ under simple vertical mixing for the two mixing scenarios as a function of temperature.

two supersaturation maxima highlights that the extent of local supersaturation depends on both the local temperature and the end members mixed to reach this temperature.

In this paper, we will examine the effects of mixing on the argon disequilibrium in a model environment to show that local measurements of argon can give basinscale vertical and eddy diffusivity estimates. In section 2 we describe the model configuration. In section 3 we demonstrate that the argon supersaturation gives a mixing history of a water parcel rather than information solely about local mixing. We discuss the effects of varying the vertical and eddy diffusivities on the gyre thermocline argon supersaturation, and in section 4 we build a theoretical model based on a scaling analysis to capture these effects. In section 5 we show that the mean equatorial Pacific Ocean supersaturation is monotonic with diffusivity. We conclude with a summary and discussion. 


\section{Model configuration}

To investigate the argon supersaturation within the model framework, we used the Los Alamos National Laboratory Parallel Ocean Program (POP) model, version 1.4. We ran the global model at fairly coarse resolution with $3^{\circ}$ longitudinal resolution and $1.4^{\circ}$ latitudinal resolution near the Poles and enhanced resolution at the equator. The model is forced with National Centers for Environmental Prediction (NCEP) winds and the bulk-NCEP formulation for the heat and salt fluxes at the surface. To simulate subgrid-scale vertical mixing, we employed the $K$-profile parameterization (KPP) mixing scheme (Large et al. 1997), which features strong diffusivity in the boundary layer and tapers to a background value of $5 \times 10^{-5} \mathrm{~m}^{2} \mathrm{~s}^{-1}$ beneath the boundary layer. This resolution is too coarse to include eddies, so we use the Gent-McWilliams scheme (Gent et al. 1995) and Redi diffusion (Redi 1982) to simulate their effects. The eddy mixing parameter is constant in space and fixed at $700 \mathrm{~m}^{2} \mathrm{~s}^{-1}$.

Along with temperature and salinity, an argon tracer is added to the model subject to the equation

$$
\frac{D A r}{D t}=\text { vertical diffusion }+\mathrm{GM}+\text { gas exchange, }
$$

where the $D / D t$ operator includes the time rate of change and advection, GM is the Gent-McWilliams and Redi mixing and parameterizes the convergence of the eddy fluxes, and "gas exchange" only operates in the surface grid box. Given the surface temperature and salinity, this tracer adjusts toward saturation at the surface according to the kinetics of gas exchange. Numerical stability requires an averaging of the SST fields from two time levels of the leapfrog scheme and an implicit gas exchange formulation assuming exponential relaxation toward equilibrium. Argon behaves as a passive tracer in the model and is advected and diffused with the same velocities and mixing coefficients as temperature and salinity.

The mixing line in Fig. 1 isolates the diathermal mixing by assuming that both surface and abyssal end members are at saturation, so only diathermal mixing affects the disequilibrium. In reality, other physical processes will affect the disequilibrium as well. The surface ocean is supersaturated by bubble injection on the order of $1 \%$ for argon (Hamme and Emerson 2002), and in high latitudes this is partially compensated by lower climatological atmospheric pressure (Well and Roether 2003). Also, subsurface solar heating elevates the supersaturation in the $10 \mathrm{~m}$ at the base of the mixed layer by approximately $0.5 \%$, assuming a temperature of $20^{\circ} \mathrm{C}$, a solar penetration of $5 \mathrm{~W} \mathrm{~m}^{-2}$ (Ohlmann et al.
1996), and a time scale of 1 month (the same order as the mixed layer subduction time scale). In the abyss, argon is approximately $1 \%-2 \%$ undersaturated. This is in part due to surface cooling (Hamme and Emerson 2002) since cooling in surface waters immediately before convection may act on a faster time scale than gas exchange. This cooling effect is partially compensated by supersaturation due to high-latitude bubble injection and modest geothermal heating (Well and Roether 2003). These effects will alter the endpoints of the mixing line in Fig. 1, causing them to lie above or below the saturation curve. Simple mixing will mix these two water masses, but the interior supersaturation profile, or the distance between the mixing line and the saturation curve, will be different relative to the simpler case in which the end members are at saturation.

To focus solely on the mixing processes, we have neglected bubble injection and atmospheric pressure effects. We use Jerlov water type 3, which allows modest subsurface heating. We effectively fix the surface and abyssal end members to saturation by using an unphysically high rate constant for gas exchange, 30 times that in the Ocean Carbon Cycle Model Intercomparison Project (OCMIP: Orr et al. 2001). By excluding bubbles and atmospheric effects and only allowing modest subsurface heating effects, the resulting thermocline argon supersaturation values will not be realistic, although we will show that our conclusions about the mechanisms that affect the argon supersaturation patterns still hold when the abyssal and surface argon concentrations are adjusted toward more realistic values. Our intent is to isolate the effects of mixing in the GCM to better understand the mixing signature. Future interpretation of real ocean data in terms of mixing will be trickier but will benefit from this understanding of mixing with the GCM.

We ran a base case for 2000 years in the manner described above, starting from a state of near-equilibration for temperature and salinity and from a state of saturation for the argon. We then compare the distribution of argon in the base case with runs with different vertical diffusivity, eddy diffusivity, and gas exchange rate. The case with higher vertical diffusivity $\left(k_{D}=\right.$ $10 \times 10^{-5} \mathrm{~m}^{2} \mathrm{~s}^{-1}$ : High Diff) was branched from the base case and run for $400 \mathrm{yr}$, while the case with lower vertical diffusivity $\left(k_{D}=1 \times 10^{-5} \mathrm{~m}^{2} \mathrm{~s}^{-1}\right.$ : Low Diff) was started from the initial conditions and run for 500 years. The case with lower eddy diffusivity $\left(\kappa_{e}=\right.$ $70 \mathrm{~m}^{2} \mathrm{~s}^{-1}$, as compared with 700 in the base case: Low GM) was branched from the base case and run for 600 years. Last, we explore the effects of gas exchange with a run with the OCMIP gas exchange rate (OCMIP Gas), run for 2000 years from the initial conditions. The 


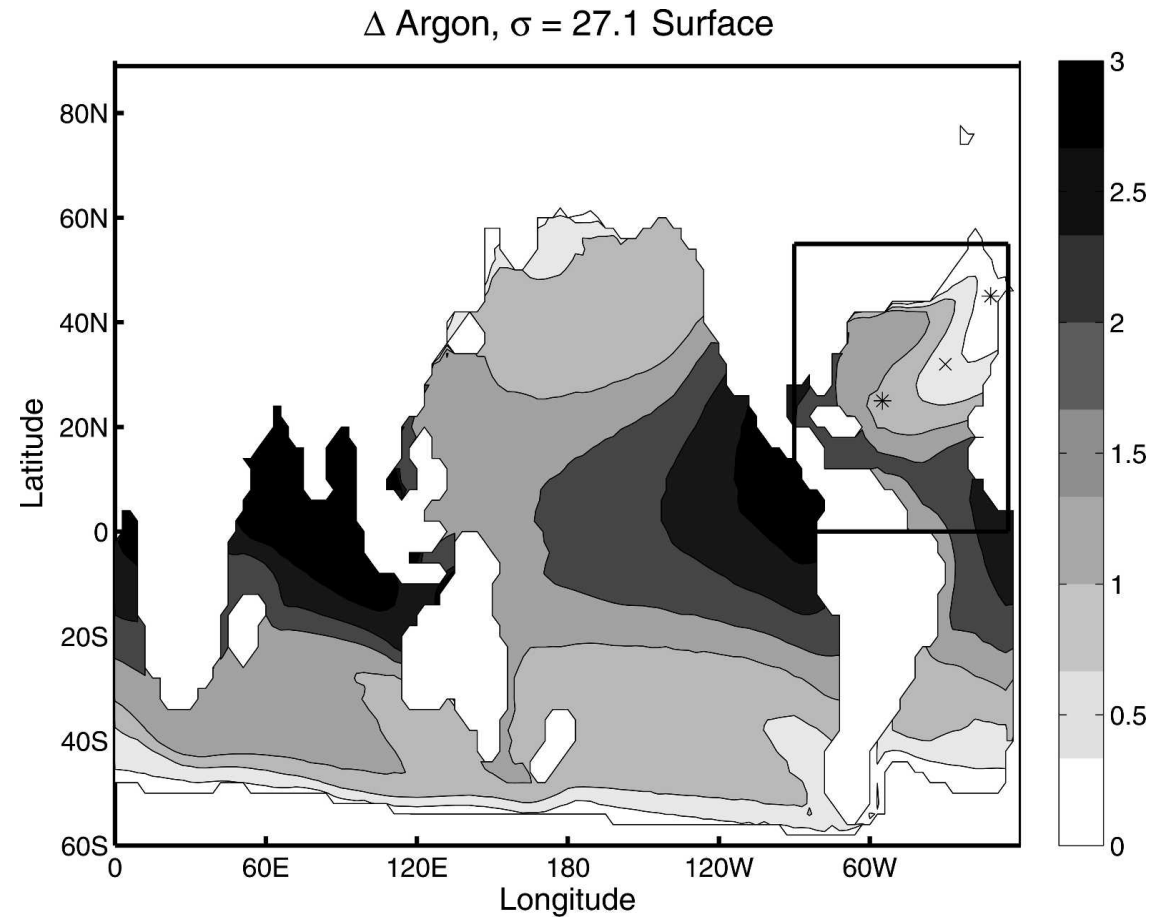

FIG. 2. The argon supersaturation (\%) in the base case of the model along the $\sigma=27.1$ density surface. The contour interval is $0.25 \%$. The inner box indicates the primary analysis region, and the $\times$ indicates the "midgyre" location in subsequent plots. The asterisks anticipate the box locations in the theoretical model to be developed.

aforementioned run times were enough to ensure that the tendency in the argon equation was an order of magnitude smaller than the other terms in the thermocline region. For analysis, we look at the timeaveraged variables over the last 10 years of the integrations.

The argon deviation from saturation is given by

$$
\Delta \mathrm{Ar}=\left(\mathrm{Ar} / \mathrm{Ar}_{\mathrm{sat}}-1\right) \times 100 \%,
$$

where $\mathrm{Ar}_{\text {sat }}$ is the saturation value for the local potential temperature and salinity. Figure 2 shows the $\Delta \mathrm{Ar}$ values in the global ocean along the $\sigma=27.1$ density surface beneath the winter convection depth. This density surface corresponds to a depth of around $700 \mathrm{~m}$ in the midthermocline in the main gyres and $1000 \mathrm{~m}$ near the equator with decreasing depths near the poleward outcrops, putting it in the portion of the thermocline that outcrops in the subpolar gyre and is not directly ventilated by Ekman pumping (Samelson and Vallis 1997). Qualitatively, the dominant feature of the plot is the supersaturation maximum near the equator, a region of strong upwelling and strong diathermal mixing. Focusing on the North Atlantic Ocean midlatitude gyre (the boxed region), the values are near zero in the poleward direction near the base of the convection zone, where the supersaturation is set back to zero. Along the path of the equatorward gyre flow, the supersaturation is small in the interior but comparatively larger in the western boundary current, a region where large crossisopycnal eddy mixing is necessary to achieve thermocline mass balance (e.g., Radko and Marshall 2003; Radko and Marshall 2004). We will investigate the vertical profile of supersaturation in the gyre (at the point indicated by the times sign) as well as the processes involved in determining the along-isopycnal gradient in the gyre.

\section{3. $\Delta \mathrm{Ar}$ in the subtropical thermocline}

Figure 3 show the $\Delta$ Ar profile using depth (Fig. 3a) and temperature (Fig. 3b) as the vertical coordinate for the cases with varying vertical and eddy diffusivities. Each case has a subsurface internal maximum in the thermocline, indicating mixing-induced supersaturation. In Fig. 3a, the maxima are at different depths, largely reflecting that the different diffusivities lead to different thermocline depths. We will use these different depths in formulating our theoretical model but, in order to focus on the supersaturation generated by mixing, focus on Fig. 3b, which mimics the plot in Fig. 1b. By showing the supersaturation in temperature space, 

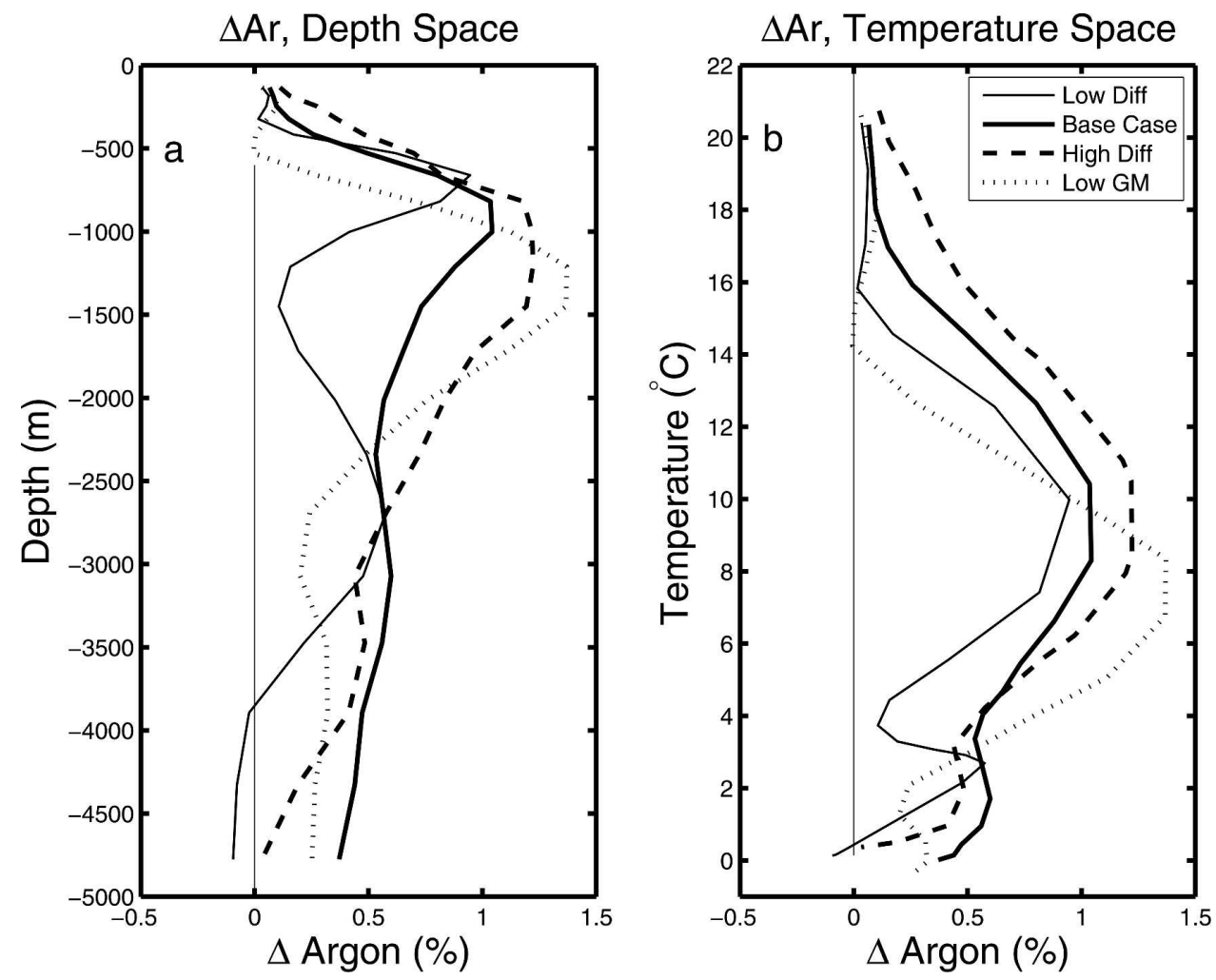

FIG. 3. (a) A depth profile of the deviation from saturation, $\Delta \mathrm{Ar}$, in percent in the midgyre location indicated in Fig. 2 for the cases with varying vertical and GM diffusivities. (b) As in (a) only plotted as a local potential temperature profile rather than depth.

Fig. 3b shows that the cases with the same eddy diffusivities (Low Diff, Base Case, and High Diff) all have maxima at the same temperature, and the values at the maxima increase with increasing diffusivity. However, the values in all cases are smaller than the internal maxima generated by simple mixing in Fig. 1b (4.7\%). This suggests that simple vertical mixing alone does not account for the extent of argon supersaturation.

Under small vertical mixing, the subtropical thermocline has an upper, ventilated thermocline and a lower, diffusively driven internal thermocline with the boundary between the two occurring at the temperature that outcrops between the subtropical and subpolar gyres (Samelson and Vallis 1997). In Fig. 3b, in the model the ventilated thermocline corresponds to temperatures between $20^{\circ}$ and $16^{\circ} \mathrm{C}$, while the internal thermocline corresponds to temperatures between $16^{\circ}$ and $3^{\circ} \mathrm{C}$ with the abyss occupying the colder temperatures. Assuming that rapid ventilation in the upper ventilated thermocline largely shields the internal thermocline from the surface conditions, the supersaturation would be zero in the ventilated thermocline and supersaturation-generating mixing would only occur between the temperature at the base of the ventilated thermocline $\left(16^{\circ} \mathrm{C}\right)$ and the temperature in the upper abyss $\left(3^{\circ} \mathrm{C}\right)$. This was illustrated by the dotted line in Fig. 1b. Comparison with Fig. 3b shows that this is borne out in the Low Diff and Low GM cases, while the Base and High Diff cases have appreciable supersaturation even in the ventilated thermocline, suggesting ventilation does not overwhelm mixing for these parameter choices.

To determine what processes maintain the observed $\Delta$ Ar vertical structure, we investigate the balance of terms in the time tendency equation for $\Delta$ Ar. Using the definition in Eq. (1) and then taking the derivative with respect to time yields

$$
\frac{\partial \Delta \mathrm{Ar}}{\partial t}=\frac{1}{\mathrm{Ar}_{\mathrm{sat}}}\left[\frac{\partial \mathrm{Ar}}{\partial t}-\frac{\mathrm{Ar}}{\mathrm{Ar}_{\mathrm{sat}}}\left(\frac{\partial \mathrm{Ar}_{\mathrm{sat}}}{\partial T} \frac{\partial T}{\partial t}+\frac{\partial \mathrm{Ar}_{\mathrm{sat}}}{\partial S} \frac{\partial S}{\partial t}\right)\right]
$$

so that the time tendency of $\Delta \mathrm{Ar}$ is in terms of the time tendencies of the three tracers and the local value and derivatives of the $\mathrm{Ar}_{\text {sat }}$. Then, given that in the interior each tracer follows 
a) $\Delta \mathrm{Ar}$ Terms

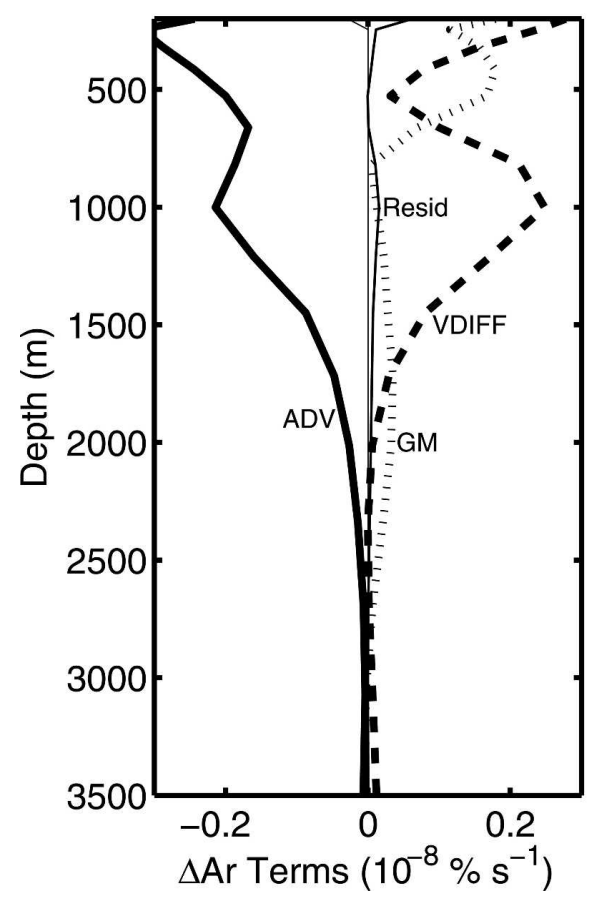

b) $\Delta \mathrm{Ar}$

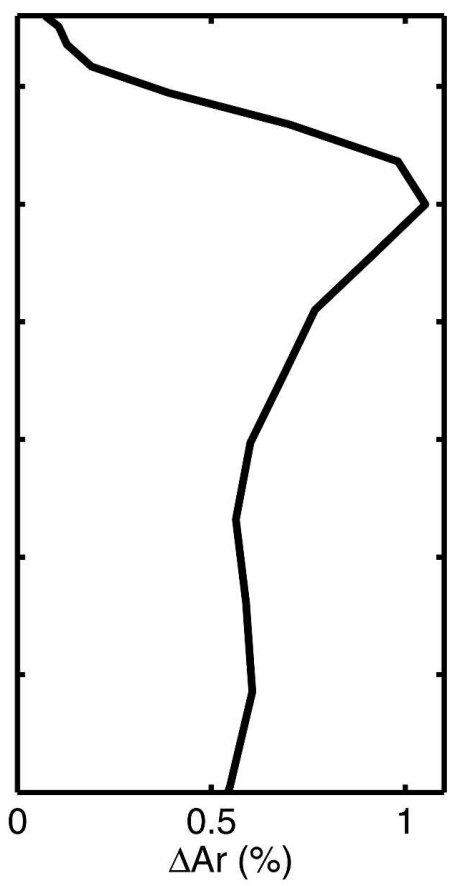

FIG. 4. The balance of terms sustaining the (a) quasi-steady state $\Delta \mathrm{Ar}$ values $\left(\% \mathrm{~s}^{-1}\right)$ and (b) $\Delta$ Ar values (\%) averaged in the midgyre location beneath $200 \mathrm{~m}$. The equation results from a nonlinear combination of the temperature, salinity, and argon tendency equations, with ADV arising from the advection terms, GM arising from the eddy parameterization, VDIFF arising from the vertical diffusion, and Resid representing the residual of these terms. Beneath $200 \mathrm{~m}$, the additional source terms are zero.

$$
\begin{aligned}
\frac{\partial \text { Tracer }}{\partial t}= & - \text { advection }+ \text { vertical diffusion } \\
& + \text { eddy diffusion }
\end{aligned}
$$

(where convection has been ignored), we can substitute to get the $\partial \Delta \mathrm{Ar} / \partial t$ in terms of the advection, vertical diffusion, and eddy diffusion of temperature, salinity, and argon. Note that the resulting $\partial \Delta \mathrm{Ar} / \partial t$ diffusion and eddy terms will not have the same mathematical form as Fickian diffusion or the GM parameterization because the $\mathrm{Ar}_{\text {sat }}$ equation is nonlinear.

Figure $4 \mathrm{a}$ shows the balance of these terms beneath the mixed layer at the same gyre location as in Fig. 3, and the $\Delta \mathrm{Ar}$ associated with this balance is shown in Fig. 4b. The term resulting from the tracer advection terms is ADV, vertical diffusion is VDIFF, eddy diffusion is GM, and the residual time tendency is Resid, and in general this term is an order of magnitude smaller than the leading-order term at each depth. In the upper ventilated thermocline (down to $600 \mathrm{~m}$ ), both vertical and eddy diffusion are sources of $\Delta \mathrm{Ar}$, and these sources are balanced by removal due to direct ventilation and the associated advection of the low $\Delta \mathrm{Ar}$ surface signal. In the lower, internal thermocline (600$1500 \mathrm{~m}$ ), where the wind stress promotes Ekman upwelling and there is no direct ventilation, the sink in $\Delta \mathrm{Ar}$ comes from the interaction with the winter convection zone in the poleward portion of the gyre and the subsequent equatorward flow, while the eddies and vertical mixing continue to be sources. Although eddies are parameterized here, this balance is similar to the temperature equation balance in an explicitly eddypermitting experiment in a similar oceanic region (Henning and Vallis 2004). The $\Delta \mathrm{Ar}$ maximum occurs close to the maximum in the vertical diffusion term, but its structure clearly depends upon the balance between the sink due to advection and the sources due to eddy mixing along isopycnals and vertical diffusion across isopycnals. The generation of $\Delta \mathrm{Ar}$ is then necessarily a three-dimensional process, rather than the one-dimensional mixing process depicted in Fig. 1.

To better demonstrate this, Fig. 5 approximates the net cross-isopycnal mass flux convergence and the integrated cross-isopycnal mass flux convergence along the gyre flow path (a line connecting the asterisks and $x$ in Fig. 2). The net mass flux convergence across an 

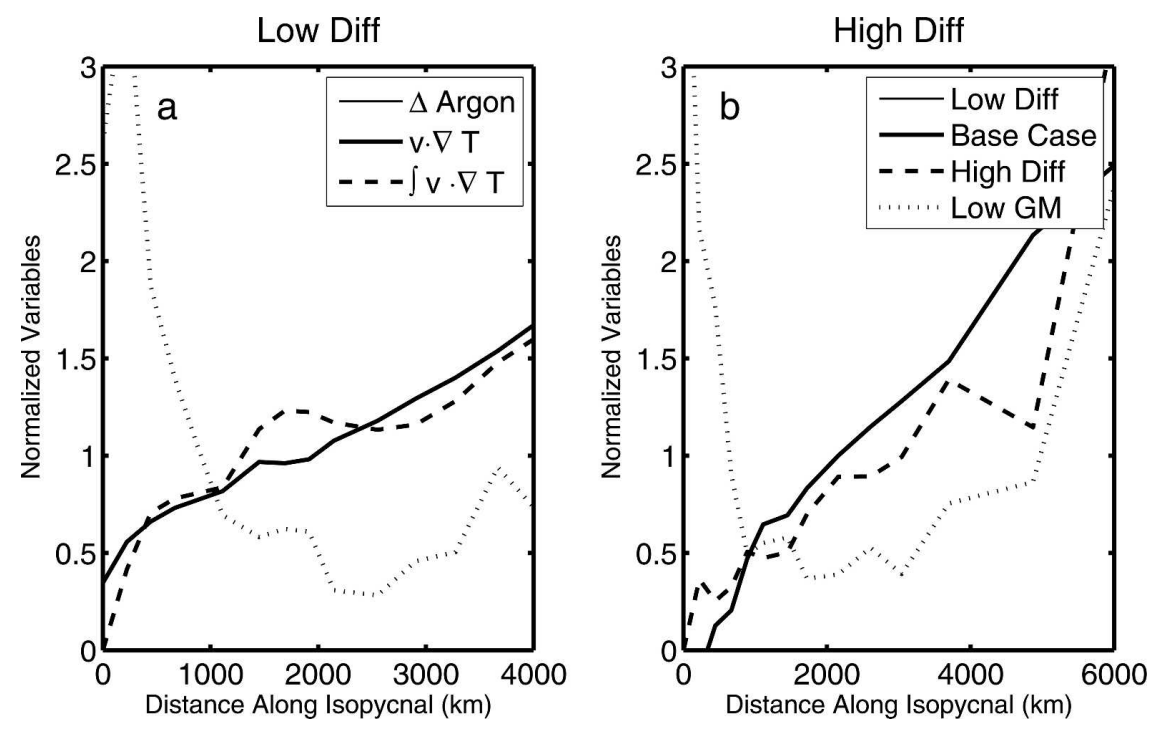

FIG. 5. The $\Delta \operatorname{Ar}$ (solid), $\mathbf{v} \cdot \boldsymbol{\nabla} T$ (dotted), and integral of $\mathbf{v} \cdot \boldsymbol{\nabla} T$ (dashed) along the path of the flow in the interior of the subtropical gyre in $\mathrm{km}$ along the 27.1- $\sigma$ surface in the (a) Low Diff and (b) High Diff cases. All three variables are normalized by their mean value.

isopycnal is given by $\mathbf{v} \cdot \nabla \rho$. If we assume the density is approximately linear and the salinity gradient is small, so that temperature is approximately constant along isopycnals, then we can approximate this flux as $\mathbf{v} \cdot \boldsymbol{\nabla} T$. This approximation is supported by plotting temperature along isopycnals and verifying that it is nearly constant. Then, $\mathbf{v} \cdot \boldsymbol{\nabla} T$ approximates the local crossisopycnal mass flux, which in steady state will equal the total vertical diffusion plus eddy mixing. In contrast, $\int \mathbf{v} \cdot \nabla T d l$, or the integral along the flow path, approximates the cumulative mixing along the path since the last time of surface contact. Figure 5 shows these quantities along with the $\Delta \mathrm{Ar}$ along the 27.1- $\sigma$ surface (the internal thermocline, at $700-\mathrm{m}$ depth), where each quantity is normalized by its mean, for the Low Diff (Fig. 5a) and High Diff (Fig. 5b) cases. In both cases, and the $\Delta$ Ar follows the shape of the cumulative mixing, $\int \mathbf{v} \cdot \boldsymbol{\nabla} T d l$, but not the shape of the local mixing, $\mathbf{v} \cdot \nabla T$. This supports the conclusion that $\Delta \mathrm{Ar}$ is not only influenced by local mixing but records the mixing history of a parcel, or the integrated sources and sinks of $\Delta \mathrm{Ar}$, since the parcel left the surface.

This net cumulative mixing, and thus the downstream $\Delta$ Ar values, will depend on the strength of the mixing along the path. To illustrate this hypothesis, Fig. 6 schematically shows two limits on the right and left with an intermediary in the middle. On the left, we illustrate the case of large horizontal flow, but no cross-isopycnal and eddy diffusion (no sources of $\Delta \mathrm{Ar}$ ). Because we are investigating the 27.1- $\sigma$ surface in the internal thermocline, this region is not directly ventilated, but we imagine a gyre where flow exits the western boundary current, enters a convection zone where the $\Delta \mathrm{Ar}$ is reset to the surface value (illustrated as position "Gyre 1 "), and then the flow turns equatorward through the main part of the gyre (illustrated as positions "Gyre 2" and "Gyre 3"). If there is no cross-isopycnal diffusion, the $\Delta \mathrm{Ar}$ will not be altered at all along the path, the $\Delta \mathrm{Ar}$ value with equal the surface value, and there will be no gradient in $\Delta \mathrm{Ar}$ along the path.

On the right is the opposite extreme where there is no along-isopycnal flow, but there is cross-isopycnal mixing. As the water mass moves equatorward from the convection zone, more and more $\Delta \mathrm{Ar}$ is added. In addition, the amount added at each point increases in the equatorward direction, since the amount of overlying heat increases, implying that the mixing end members are "farther apart" in temperature space and there is a larger potential $\Delta \mathrm{Ar}$ (as in Fig. 1). The net effect of the cumulative mixing is a gradient of low $\Delta$ Ar poleward at Gyre 1 to larger $\Delta A r$ equatorward at Gyre 3.

In the middle is the intermediary case, in which there is both cross-isopycnal mixing and along-isopycnal advection. As the parcel moves from Gyre 1 to Gyre 3, there is a contribution from the local cross-isopycnal mixing at each point, but the extent to which this mixing affects the watermass $\Delta \mathrm{Ar}$ depends on the relative advective and diffusive time scales. Switching to an Eulerian perspective and observing the local balance at Gyre 3, diffusion is a local source of $\Delta \mathrm{Ar}$, but the advection is bringing in lower $\Delta \mathrm{Ar}$ water from upstream, 


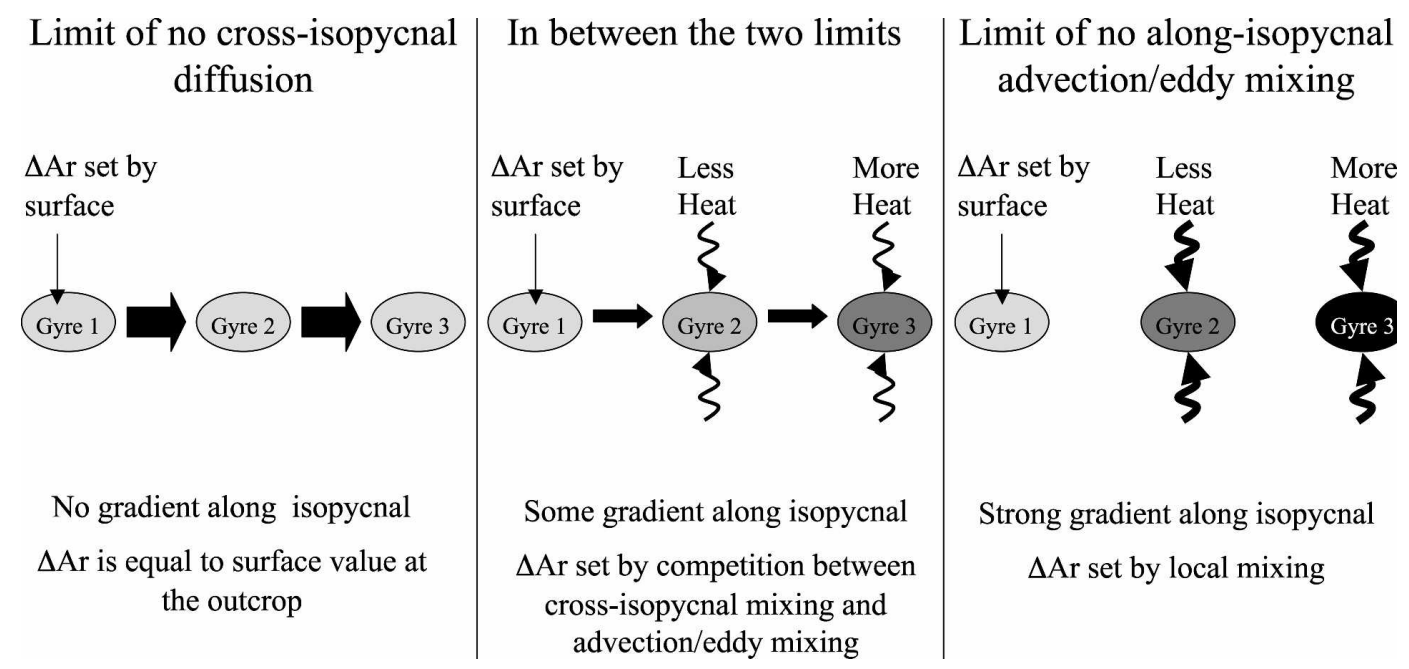

FIG. 6. Schematic showing the processes generating a $\Delta$ Ar gradient along the flow path for hypothetical positions: Gyre 1 near the poleward convection region, and Gyre 2 and Gyre 3 downstream. (left) In the limit of no vertical diffusion, the Gyre 1 value is set by the convection, and the advection spreads the signal along the isopycnal so that there is no gradient. (right) In the limit of no advection, the vertical diffusion mixes water mass from above and below the isopycnal to create the local $\Delta$ Ar. Because the amount of heat above, and thus the potential $\Delta \mathrm{Ar}$, increases in the equatorward direction, there is a gradient in $\Delta \mathrm{Ar}$ along the isopycnal. (middle) Between the two limits, the final gradient is determined by competition between diffusion, which acts to increase the gradient, and advection, which acts to decrease the gradient.

so it represents a local sink of $\Delta \mathrm{Ar}$. If the advection is fast, the cross-isopycnal mixing at each location will have a smaller contribution and the gradient along the path will be small. Thus, the gradient in $\Delta \mathrm{Ar}$ along the path gives information about the relative time scales of the advection versus the cross-isopycnal mixing.

To confirm that the $\Delta$ Ar gradient along the flow path varies with diffusivity, Fig. 7 shows the $\Delta \mathrm{Ar}$ along the 27.1- $\sigma$ surface in the box indicated in Fig. 2 for the cases with varying vertical and eddy diffusivities. The core of the gyre flow is shown for each case with the $\times$, and these locations are found by starting in the northeastern corner and tracing the velocity vectors down to $22^{\circ} \mathrm{N}$. Looking at the Low Diff, Base, and High Diff cases, as the diffusion is increased, the gradient along this flow path increases. In addition, the $\Delta \mathrm{Ar}$ in the equatorial region and in the region located from longitude $290^{\circ}$ to $310^{\circ}$ between $30^{\circ}$ and $40^{\circ} \mathrm{N}$ also increases for increasing vertical diffusivity. The latter region encompasses the western boundary current along with the region where the potential vorticity contours are closed and the flow recirculates without being reset to surface values in the convection region to the north.

In general, eddy mixing tends to mix tracer down the mean tracer gradient. In a comparison of the cases with varying eddy diffusivity (Base and Low GM cases), the gyre gradient along the $X$ also increases for increasing eddy diffusivity. In particular, in the Low GM case, there is a larger high- $\Delta \mathrm{Ar}$ western boundary region and larger $\Delta \mathrm{Ar}$ at the equator with smaller values along the flow path. This suggests that the GM parameterization is mixing $\Delta \mathrm{Ar}$ from these high- $\Delta \mathrm{Ar}$ regions into the low- $\Delta \mathrm{Ar}$ gyre core, demonstrating how downgradient eddy mixing acts as a local source of $\Delta \mathrm{Ar}$ along the path of the flow.

Thus, at any one point, the local $\Delta \mathrm{Ar}$ depends on the balance between advection of low $\Delta \mathrm{Ar}$ from upstream (sink), eddy mixing of high $\Delta \mathrm{Ar}$ from upgradient (source), and cross-isopycnal mixing from the vertical diffusion (source). The local relative contribution of each will depend on the relative time scale of each process with fast processes exerting more control on the local $\Delta$ Ar. The overall effect of this competition on a given water mass is a gradient downstream, with the magnitude of the gradient depending on the strength of the mixing.

\section{Large-scale mean diffusivity and a simple mixing model}

Based on these observations, we have constructed a simple scaling model to relate the gradient of the gyre core $\Delta$ Ar to vertical and GM diffusivities. We consider five locations along a given isopycnal with approximately constant and known temperature $\left(12^{\circ} \mathrm{C}\right.$ for $\sigma=$ 27.1) and a constant salinity of 35 psu, as illustrated in 

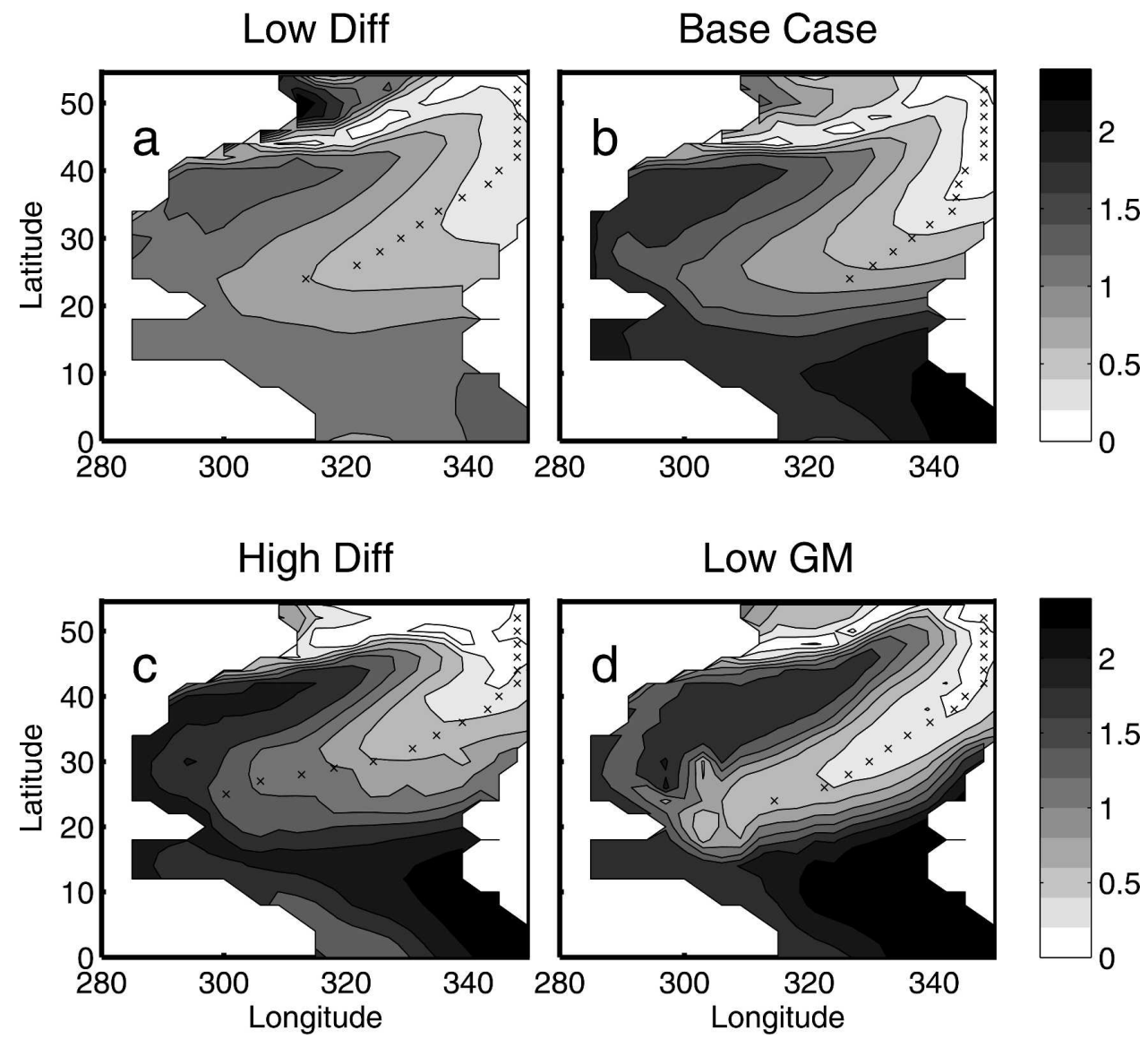

FIG. 7. The $\Delta \mathrm{Ar}$ in the subtropical gyre along the 27.1- $\sigma$ surface for the cases with a vertical diffusivity of (a) $1 \times 10^{-5} \mathrm{~m}^{2} \mathrm{~s}^{-1}$ (Low Diff), (b) $5 \times 10^{-5} \mathrm{~m}^{2} \mathrm{~s}^{-1}$ (Base Case), and (c) $1 \times 10^{-4} \mathrm{~m}^{2} \mathrm{~s}^{-1}$ (High Diff). (d) The case with one-tenth the GM diffusivity (Low GM). All have the same color scheme, and the contour interval is $0.3 \%$. The times signs indicate the grid points along the path of the flow that we will use to compare the GCM gradient with the theoretical mixing model gradient. They are found by starting in the northeastern corner and tracing the velocity vectors down to $22^{\circ} \mathrm{N}$.

Fig. 8: one in the convection region in the poleward direction (Gyre 1), one located downstream in the midgyre (Gyre 2), a third even farther downstream in the equatorward portion of the gyre (Gyre 3), one directly at the equator (EQ), and one in the western boundary current and recirculation region (WB, referred to simply as western boundary region henceforth). The three gyre boxes are the analogs of the asterisks and $\times$ in Fig. 2. We specify the $\Delta \mathrm{Ar}$ in gyre 1, $\mathrm{WB}$, and $\mathrm{EQ}$, along with the values at the surface and in the abyss, and then calculate the value in Gyre 2 and Gyre 3 in an attempt to reproduce the GCM $\Delta$ Ar values along the $\times$ in Fig. 7. This can be visualized as setting the values along the edges of a three-dimensional bounding surface and determining the resulting values inside the surface.

To construct the model, we begin with the balance for the physical tracer, argon, and from that we will construct the balance for $\Delta \mathrm{Ar}$. We assume the local Ar results from vertical mixing between the mixed layer and the abyss, lateral mixing from the adjoining boxes, and advection from upstream. We can scale the tracer equation, assuming that for each peripheral box and each local box, the source terms in the argon equation have the form $\left(\operatorname{Ar}_{p}-\mathrm{Ar}_{l}\right) / \tau_{p}$, where $\operatorname{Ar}_{p}$ is the amount of argon in the peripheral box, $\mathrm{Ar}_{l}$ is the local value, and $\tau_{p}$ is the time scale of the particular process (eddy mixing, vertical mixing, or advection). In this way, if $\mathrm{Ar}_{l}$ is lower than $\mathrm{Ar}_{p}$, the term is an overall source, while if $\operatorname{Ar}_{p}$ is lower than $\mathrm{Ar}_{l}$, the term is a sink. Since the time scales for the vertical diffusion, eddy diffusion, and advection are given by

$$
\tau_{D}=\frac{D^{2}}{\kappa_{D}}, \tau_{e}=\frac{L^{2}}{\kappa_{e}}, \text { and } \tau_{v}=\frac{L}{V}
$$

the overall argon equation scales as 


\section{Mixing Model: Competition Between Mean Advection, Eddy Flux Convergence, and Cross-Isopycnal Diffusion}

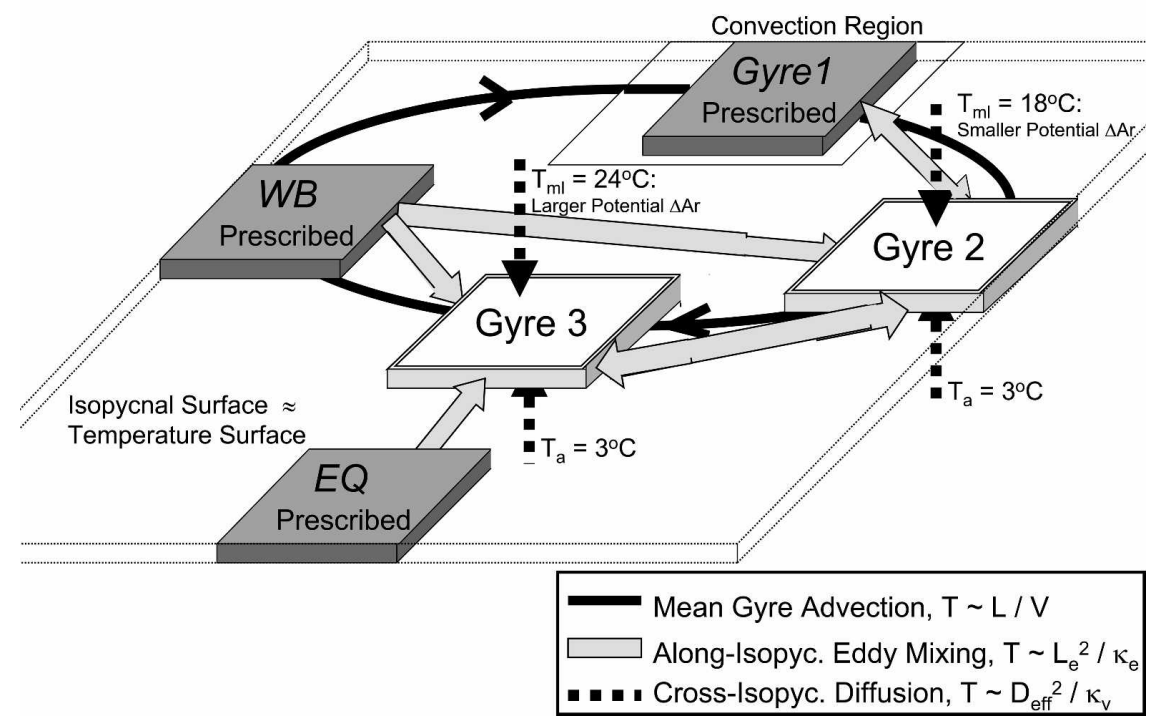

FIG. 8. A schematic showing the box locations for the theoretical mixing model. We prescribe the values in the Gyre 1 (near the convection region), the western boundary/ recirculation (WB), and equatorial (EQ) locations, along with the values above in the mixed layer and below in the abyss. We also prescribe the local temperature, assumed constant along the isopycnal, the mixed layer and abyssal temperatures, and the advective length scale $L$, the eddy length scale $L_{e}$, and the diffusive depth scale $D_{\text {eff }}$. We can then solve for the interior values of $\Delta \mathrm{Ar}$ at Gyre 2 and Gyre 3 based on the competition between advection (solid line), along-isopycnal eddy mixing from upgradient (gray arrows), and vertical diffusion from above and below (dashed arrows)

$$
\begin{aligned}
\frac{\Delta[\mathrm{Ar}]}{\Delta T}=0 & =\frac{\kappa_{D}}{D_{\mathrm{ml}}^{2}}\left(\mathrm{Ar}_{\mathrm{ML}}-\mathrm{Ar}_{L}\right)+\frac{\kappa_{D}}{D_{a}^{2}}\left(\mathrm{Ar}_{A}-\mathrm{Ar}_{L}\right)+\frac{\kappa_{e}}{L_{e}^{2}}\left(\mathrm{Ar}_{\mathrm{WB}}-\mathrm{Ar}_{L}\right)+\frac{\kappa_{e}}{L_{e}^{2}}\left(\mathrm{Ar}_{\mathrm{UG}}-\mathrm{Ar}_{L}\right) \\
& +\frac{\kappa_{e}}{L_{e}^{2}}\left(\mathrm{Ar}_{\mathrm{DG}}-\mathrm{Ar}_{L}\right)+\frac{V}{L}\left(\mathrm{Ar}_{\mathrm{US}}-\mathrm{Ar}_{L}\right),
\end{aligned}
$$

where $A r_{\mathrm{ML}}, \mathrm{Ar}_{A}, \mathrm{Ar}_{\mathrm{WB}}, \mathrm{Ar}_{\mathrm{UG}}, \mathrm{Ar}_{\mathrm{DG}}, \mathrm{Ar}_{V}, \mathrm{Ar}_{\mathrm{US}}$, and $\mathrm{Ar}_{L}$ are the amounts of argon in the mixed layer, abyssal, western boundary, upgradient, downgradient, upstream, and local water masses, respectively. The first two terms on the right-hand side represent vertical mixing from the abyss and from the mixed layer, where the distance between these two locations and the local isopycnal is distinct $\left(D_{\mathrm{ml}}\right.$ and $\left.D_{a}\right)$ and $\kappa_{D}$ is the vertical diffusivity (assumed constant). Terms 3-5 represent eddy mixing from the western boundary current and upgradient and downgradient water masses, where $L_{e}$ is the characteristic length scale between the boxes (assumed constant for simplicity) and $\kappa_{e}$ is the eddy diffusivity. The last term is the advection of argon from upstream, where $V$ is the characteristic velocity along the given isopycnal and $L$ is the distance between the boxes.
For the diffusive terms in this equation, we saw in Fig. 3 that the $\Delta$ Ar maximum occurs over a wider range of temperatures for increasing diffusivities: for the Low Diff case, mixing seems to occur between the abyss and the base of the ventilated thermocline, while for the High Diff case, mixing seems to occur from the abyss all the way up to the mixed layer. Operationally, in constructing a model we do not wish to trace all of the layers up to the surface and to vary the temperature range of the mixing; thus, we make the simplifying assumption that the mixing occurs between the mixed layer and the abyss for all cases. However, we can partially correct for this simplification by noting that there is information about the mixing depth scale in the local temperature profile.

In general, $D_{\mathrm{ml}}$ and $D_{a}$ are not the same. The mixing model turns out to be very sensitive to the choice of 
the depth scales since the vertical mixing is the largest potential source of $\Delta \mathrm{Ar}$. The selection of the depths simply by inspection tends to be rather ad hoc, especially for $D_{a}$, since the abyssal boundary can extend over many hundreds of meters. However, we can merge them into a single effective depth scale by noting that the temperature end members are at the same physical depths as the argon end members, and these end members must mix in relative proportions consistent with the generation of the local temperature $T_{L}$. Then, using the known local, mixed layer, and abyssal temperatures along with the column-mean observed temperature curvature, $\partial^{2} T / \partial z^{2}$, we can define

$$
D_{\mathrm{ml}}^{2} \sim\left|\frac{T_{\mathrm{ML}}-T_{L}}{\partial^{2} T / \partial z^{2}}\right| \text { and } D_{a}^{2} \sim\left|\frac{T_{L}-T_{A}}{\partial^{2} T / \partial z^{2}}\right| .
$$

Then, the diffusive terms in Eq. (5) become

$$
\text { diffusive terms }=\kappa_{D}\left|\frac{\partial^{2} T}{\partial z^{2}}\right|\left(\frac{\mathrm{Ar}_{\mathrm{ML}}-\mathrm{Ar}_{L}}{T_{\mathrm{ML}}-T_{L}}+\frac{\mathrm{Ar}_{A}-\mathrm{Ar}_{L}}{T_{L}-T_{A}}\right)
$$

which can be rearranged into the form

$$
\text { diffusive terms }=\kappa_{D}\left|\frac{\partial^{2} T}{\partial z^{2}}\right| \frac{\left(T_{\mathrm{ML}}-T_{A}\right)}{\left(T_{\mathrm{ML}}-T_{L}\right)\left(T_{L}-T_{A}\right)}\left[\frac{\left(T_{L}-T_{A}\right)}{\left(T_{\mathrm{ML}}-T_{A}\right)}\left(\mathrm{Ar}_{\mathrm{ML}}-\mathrm{Ar}_{L}\right)+\frac{\left(T_{\mathrm{ML}}-T_{L}\right)}{\left(T_{\mathrm{ML}}-T_{A}\right)}\left(\mathrm{Ar}_{A}-\mathrm{Ar}_{L}\right)\right],
$$

or letting

$$
C_{\mathrm{ML}}=\frac{\left(T_{L}-T_{A}\right)}{\left(T_{\mathrm{ML}}-T_{A}\right)}, C_{A}=\frac{\left(T_{\mathrm{ML}}-T_{L}\right)}{\left(T_{\mathrm{ML}}-T_{A}\right)}, \quad \text { and } \quad D_{\mathrm{eff}}=\left[\frac{\left(T_{\mathrm{ML}}-T_{L}\right)\left(T_{L}-T_{A}\right)}{\left|\partial^{2} T / \partial z^{2}\right|\left(T_{\mathrm{ML}}-T_{A}\right)}\right]^{1 / 2},
$$

then

$$
\begin{aligned}
\text { diffusive terms }= & \frac{\kappa_{D}}{D_{\text {eff }}^{2}}\left[C_{\mathrm{ML}}\left(\mathrm{Ar}_{\mathrm{ML}}-\mathrm{Ar}_{L}\right)\right. \\
& \left.+C_{A}\left(\mathrm{Ar}_{A}-\mathrm{Ar}_{L}\right)\right] .
\end{aligned}
$$

This expression captures the fact that the mixed layer and abyssal water masses are mixed in known propor-

tions, $C_{\mathrm{ML}}$ and $C_{A}$, so that the local temperature is $T_{L}$ (the reader can verify that $C_{\mathrm{ML}}+C_{A}=1$ and $\left.C_{\mathrm{ML}} T_{\mathrm{ML}}+C_{A} T_{A}=T_{L}\right)$. The effective depth scale is determined by the temperature curvature and establishes a systematic depth scale for use in the mixing model.

Then, defining $\tau_{D}=\kappa_{D} / D_{\text {eff }}^{2}$, defining inverse time scales as $\tau^{-1}$, and rearranging Eq. (5) gives

$$
\mathrm{Ar}_{L} \sim \frac{\tau_{D}^{-1}\left(C_{\mathrm{ML}} \mathrm{Ar}_{\mathrm{ML}}+C_{A} \mathrm{Ar}_{A}\right)+\tau_{e}^{-1}\left(\mathrm{Ar}_{\mathrm{WB}}\right)+\tau_{e}^{-1}\left(\mathrm{Ar}_{\mathrm{UG}}\right)+\tau_{e}^{-1}\left(\mathrm{Ar}_{\mathrm{DG}}\right)+\tau_{V}^{-1}\left(\mathrm{Ar}_{\mathrm{US}}\right)}{\left(\tau_{D}^{-1}+3 \tau_{e}^{-1}+\tau_{V}^{-1}\right)}
$$

This equation defines $\mathrm{Ar}_{L}$ as a mixture of all the other water masses, where the relative proportion of each water mass is weighted by the inverse time scale of the mixing process (so that slower processes make less of a contribution).

We next define

$$
a^{\prime}=\frac{\tau_{D}^{-1}}{\tau_{D}^{-1}+3 \tau_{e}^{-1}+\tau_{V}^{-1}} \text { and } a^{\prime \prime}=\frac{3 \tau_{e}^{-1}}{\tau_{D}^{-1}+3 \tau_{e}^{-1}+\tau_{V}^{-1}}
$$

and we can now change Eq. (9) into an equation for $\Delta \mathrm{Ar}$ by subtracting and dividing by $\mathrm{Ar}_{\mathrm{sat}, L}$, the saturation argon along the isopycnal, on both sides:

$$
\begin{aligned}
& \frac{\mathrm{Ar}_{L}-\mathrm{Ar}_{\mathrm{sat}, L}}{\mathrm{Ar}_{\mathrm{sat}, L}} \sim a^{\prime}\left[\mathrm{C}_{\mathrm{ML}} \frac{\left(\mathrm{Ar}_{\mathrm{ML}}-\mathrm{Ar}_{\mathrm{sat}, L}\right)}{\mathrm{Ar}_{\mathrm{sat}, L}}+\mathrm{C}_{A} \frac{\left(\mathrm{Ar}_{A}-\mathrm{Ar}_{\mathrm{sat}, L}\right)}{\mathrm{Ar}_{\mathrm{sat}, L}}\right] \\
& +\frac{a^{\prime \prime}}{3}\left(\frac{\operatorname{Ar}_{\mathrm{WB}}-\mathrm{Ar}_{\mathrm{sat}, L}}{\mathrm{Ar}_{\mathrm{sat}, L}}+\frac{\mathrm{Ar}_{\mathrm{UG}}-\mathrm{Ar}_{\mathrm{sat}, L}}{\mathrm{Ar}_{\mathrm{sat}, L}}+\frac{\mathrm{Ar}_{\mathrm{DG}}-\mathrm{Ar}_{\mathrm{sat}, L}}{\mathrm{Ar}_{\mathrm{sat}, L}}\right)+\left(1-a^{\prime}-a^{\prime \prime}\right) \frac{\left(\mathrm{Ar}_{\mathrm{US}}-\mathrm{Ar}_{\mathrm{sat}, L}\right)}{\mathrm{Ar}_{\mathrm{sat}, L}} \text {. }
\end{aligned}
$$

Since all the boxes located on the local isopycnal are assumed to be at the same temperature and salinity, they all have the same $\operatorname{Ar}_{\text {sat }}$ value, $\operatorname{Ar}_{\mathrm{sat}, L}$. However, the abyssal and mixed layer boxes have a different
$\mathrm{Ar}_{\mathrm{sat}}$ value consistent with their own local temperatures, $T_{A}$ and $T_{\mathrm{ML}}$, respectively. Recalling that $\Delta \mathrm{Ar}=\left(\mathrm{Ar}-\mathrm{Ar}_{\mathrm{sat}}\right) / \mathrm{Ar}_{\mathrm{sat}}$, then algebraic manipulation gives 


$$
\frac{\left(\mathrm{Ar}_{\mathrm{ML}}-\mathrm{Ar}_{\mathrm{sat}, L}\right)}{\mathrm{Ar}_{\text {sat }, L}}=\frac{\mathrm{Ar}_{\text {sat }, \mathrm{ML}}}{\mathrm{Ar}_{\text {sat } . L}}\left(\frac{\mathrm{Ar}_{\mathrm{ML}}-\mathrm{Ar}_{\text {sat, } \mathrm{ML}}+\mathrm{Ar}_{\text {sat }, \mathrm{ML}}-\mathrm{Ar}_{\text {sat }, L}}{\mathrm{Ar}_{\text {sat }, \mathrm{ML}}}\right)=\frac{\mathrm{Ar}_{\text {sat }, \mathrm{ML}}}{\mathrm{Ar}_{\text {sat }, L}}\left(\Delta \mathrm{Ar}_{\mathrm{ML}}+1\right)-1
$$

and similarly for the abyss. Then, the equation for $\Delta \mathrm{Ar}_{\mathrm{L}}$ finally becomes

$$
\begin{aligned}
\Delta \mathrm{Ar}_{L} \sim a^{\prime} & \left\{C_{\mathrm{ML}}\left[\frac{\mathrm{Ar}_{\mathrm{sat}, \mathrm{ML}}}{\operatorname{Ar}_{\mathrm{sat}, L}}\left(\Delta \mathrm{Ar}_{\mathrm{ML}}+1\right)-1\right]+C_{A}\left[\frac{\mathrm{Ar}_{\mathrm{sat}, A}}{\mathrm{Ar}_{\mathrm{sat}, L}}\left(\Delta \mathrm{Ar}_{A}+1\right)-1\right]\right\} \\
+ & \frac{a^{\prime \prime}}{3}\left(\Delta \mathrm{Ar}_{\mathrm{WB}}+\Delta \mathrm{Ar}_{\mathrm{UG}}+\Delta \mathrm{Ar}_{\mathrm{DG}}\right)+\left(1-a^{\prime}-a^{\prime \prime}\right) \Delta \mathrm{Ar}_{\mathrm{US}},
\end{aligned}
$$

or defining for each box

$$
\begin{aligned}
B_{n}= & C_{\mathrm{ML}}\left[\frac{\mathrm{Ar}_{\mathrm{sat}, \mathrm{ML}, n}}{\mathrm{Ar}_{\mathrm{sat}, L}}\left(\Delta \mathrm{Ar}_{\mathrm{ML}}+1\right)-1\right] \\
& +C_{A}\left[\frac{\mathrm{Ar}_{\mathrm{sat}, A}}{\operatorname{Ar}_{\mathrm{sat}, L}}\left(\Delta \mathrm{Ar}_{\mathrm{A}}+1\right)-1\right],
\end{aligned}
$$

then for all the model boxes,

$$
\begin{aligned}
\Delta \mathrm{Ar}_{\mathrm{WB}} & =\text { prescribed, } \\
\Delta \mathrm{Ar}_{\mathrm{EQ}} & =\text { prescribed } \\
\Delta \mathrm{Ar}_{1} & =\text { prescribed, } \\
\Delta \mathrm{Ar}_{2} & =a^{\prime} B_{2}+\frac{a^{\prime \prime}}{3}\left(\Delta \mathrm{Ar}_{\mathrm{WB}}+\Delta \mathrm{Ar}_{3}+\Delta \mathrm{Ar}_{1}\right)+\left(1-a^{\prime}-a^{\prime \prime}\right) \Delta \mathrm{Ar}_{1}, \quad \text { and } \\
\Delta \mathrm{Ar}_{3} & =a^{\prime} B_{3}+\frac{a^{\prime \prime \prime}}{3}\left(\Delta \mathrm{Ar}_{\mathrm{WB}}+\Delta \mathrm{Ar}_{\mathrm{EQ}}+\Delta \mathrm{Ar}_{2}\right)+\left(1-a^{\prime}-a^{\prime \prime}\right) \Delta \mathrm{Ar}_{2} .
\end{aligned}
$$

We can now eliminate $\Delta \mathrm{Ar}_{3}$ from the last two equations to give

$$
\Delta \mathrm{Ar}_{2}=\frac{a^{\prime}\left(B_{2}+\frac{a^{\prime \prime}}{3} B_{3}\right)+\frac{a^{\prime \prime}}{3}\left(1+\frac{a^{\prime \prime}}{3}\right) \Delta \mathrm{Ar}_{\mathrm{WB}}+\left(\frac{a^{\prime \prime}}{3}\right)^{2} \Delta \mathrm{Ar}_{\mathrm{EQ}}+\left(1-a^{\prime}-\frac{2}{3} a^{\prime \prime}\right) \Delta \mathrm{Ar}_{1}}{\left[1-\left(\frac{a^{\prime \prime}}{3}\right)^{2}-\frac{a^{\prime \prime}}{3}\left(1-a^{\prime}-a^{\prime \prime}\right)\right]} .
$$

This can be then be used to solve for $\Delta \mathrm{Ar}_{3}$.

To apply this model to the GCM results along the 27.1- $\sigma$ surface $\left(T \approx 12^{\circ} \mathrm{C}\right)$, we must specify the inverse time scales, and thus weighting factors, for advection, diffusion, and eddy mixing. For advection, we find that the mean velocity scale for all cases along the $\times$ on the 27.1- $\sigma$ surface is $0.2 \mathrm{~cm} \mathrm{~s}^{-1}$, while the mean distance between the box locations (or half the distance between the endpoints $X$ in Fig. 7) for eddy mixing and advection is $L \sim L_{e} \sim 2500 \mathrm{~km}$. For the diffusion, we find the average temperature profile at the locations specified by the $\times$ in Fig. 7, and for simplicity we fit a secondorder polynomial to the profile, approximate as the constant resulting from that fit, and input that constant to calculate $D_{\text {eff }}$.

We then prescribe the necessary bounding $\Delta \mathrm{Ar}$ values from the GCM for each case by averaging the values at the surface, at the Gyre 1 location, at the equator, and in the western boundary region. All these param- eters are shown in Table 1 for each case. Last, we calculate the $\mathrm{Ar}_{\text {sat }}$ values along the isopycnal surface $\left(T_{1}=\right.$ $\left.12^{\circ} \mathrm{C}, S=35 \mathrm{psu}\right)$, in the abyss $\left(T_{A}=3^{\circ} \mathrm{C}, S=35 \mathrm{psu}\right)$, and at the surface $\left(T_{\mathrm{ML}, 2}=18^{\circ} \mathrm{C}, T_{\mathrm{ML}, 3}=24^{\circ} \mathrm{C}\right.$, $S=35 \mathrm{psu}$ ).

The results for the gyre gradient from the theoretical model in comparison with the values in the full GCM are shown in Fig. 9a. The $\Delta \mathrm{Ar}$ values are plotted as a function of position along the path from the convection region. The solid lines show the results from the theoretical model, with the circles showing the position of the boxes. The results from the GCM are shown with the symbols, and the Low Diff case is displaced 1\% upward in the interest of figure clarity. In general, the agreement is favorable for all the cases we ran, suggesting that despite the simplifying assumption that the mixing occurs all the way to the surface, the model is able to adequately capture the competition between the sources and sinks of $\Delta$ Ar. Table 1 quantifies the agree- 
TABLE 1. Parameters and results from the theoretical mixing model, $L=L_{e}=2500 \mathrm{~km}$.

\begin{tabular}{|c|c|c|c|c|c|c|c|c|c|c|c|}
\hline \multirow[b]{3}{*}{ Case } & \multirow{3}{*}{$\frac{\text { From GCM }}{D_{\text {eff }}(\mathrm{m})}$} & \multicolumn{3}{|c|}{$\begin{array}{l}\text { Mixing weights based on } \\
\text { relative time scales }\end{array}$} & \multirow{2}{*}{\multicolumn{5}{|c|}{ Boundary values taken from the GCM }} & \multicolumn{2}{|c|}{ Results } \\
\hline & & \multirow[b]{2}{*}{$a^{\prime}$ diffusion } & \multirow[b]{2}{*}{$a^{\prime \prime}$ eddy } & \multirow{2}{*}{$\begin{array}{l}\left(1-a^{\prime}-a^{\prime \prime}\right) \\
\text { advection }\end{array}$} & & & & & & Predicted & GCM \\
\hline & & & & & $\Delta \mathrm{Ar}_{1}$ & $\Delta \mathrm{Ar}_{S}$ & $\Delta \mathrm{Ar}_{A}$ & $\Delta \mathrm{Ar}_{\mathrm{WB}}$ & $\Delta \mathrm{Ar}_{\mathrm{EQ}}$ & slope & slope \\
\hline Low Diff & 490 & 0.04 & 0.29 & 0.67 & $0.3 \%$ & $0 \%$ & $0.2 \%$ & $1.5 \%$ & $1.4 \%$ & 0.04 & 0.05 \\
\hline Base & 710 & 0.08 & 0.27 & 0.65 & $0 \%$ & $0 \%$ & $0.5 \%$ & $1.9 \%$ & $2.6 \%$ & 0.09 & 0.10 \\
\hline High Diff & 770 & 0.13 & 0.26 & 0.61 & $0 \%$ & $0 \%$ & $0.5 \%$ & $2.1 \%$ & $2.6 \%$ & 0.13 & 0.14 \\
\hline Low GM & 780 & 0.09 & 0.04 & 0.87 & $0.1 \%$ & $0 \%$ & $0 \%$ & $1.9 \%$ & $2.9 \%$ & 0.05 & 0.05 \\
\hline OCMIP Gas & 710 & 0.08 & 0.27 & 0.65 & $-0.7 \%$ & $-0.3 \%$ & $-2.0 \%$ & $0.5 \%$ & $-0.6 \%$ & 0.05 & 0.05 \\
\hline
\end{tabular}

ment for all cases by comparing the slopes of the lines in the GCM and theoretical model gradients for all cases.

As discussed in section 2, we used fast gas exchange at the surface in the interest of simplicity; however, in the real ocean there is slower gas exchange, introducing a deviation from saturation at the surface and also in the abyss, where the $\Delta \mathrm{Ar}$ partially reflects the surface signal at the time of convection near the poles. For our model, this means that the concentrations for the available water masses along the bounding surface (mixed layer, abyss, Gyre 1, WB, and EQ) must be altered, but the values inside this surface (Gyre 2 and Gyre 3) will still be determined by the relative mixing of these water masses. To test this statement, we also show a case with slower (more realistic) gas exchange, OCMIP Gas. It has the same physical parameters and mixing coefficients as the base case, but has different bounding $\Delta \mathrm{Ar}$ values, as shown in Table 1. The agreement between the GCM and the theoretical model is also good in this case, suggesting that, as long as the bounding $\Delta \mathrm{Ar}$ values are input correctly, the model can be applied. For the more realistic ocean cases, where bubble effects and varying solar heating will also affect the mixed layer concentrations, this implies the model will also work, provided the bubble and heating effects are confined to the mixed layer and there is no direct heating at thermocline depths.

The scaling model requires input of the $\Delta \mathrm{Ar}$ at a number of points in order to define the bounding surface. The number of points required is large because the gyre must be separated from all regions with differing dynamic balances, including the equator, mixed layer, abyss, and western boundary current. We wish to emphasize, though, that we have not "tuned" the scaling model in any way; the agreement comes naturally from the input of the averaged GCM values on the bounding surface.

To demonstrate the sensitivity of the scaling model, Fig. $9 \mathrm{~b}$ shows the results of the model when the base case bounding $\Delta \mathrm{Ar}$ values are used, but the vertical and eddy diffusivities from the other cases are used to find the inverse time scales. Also shown are the circles representing the GCM $\triangle \mathrm{Ar}$ values for the Base Case. In this portion of parameter space, there is a clear distinction between the theoretical model predictions for
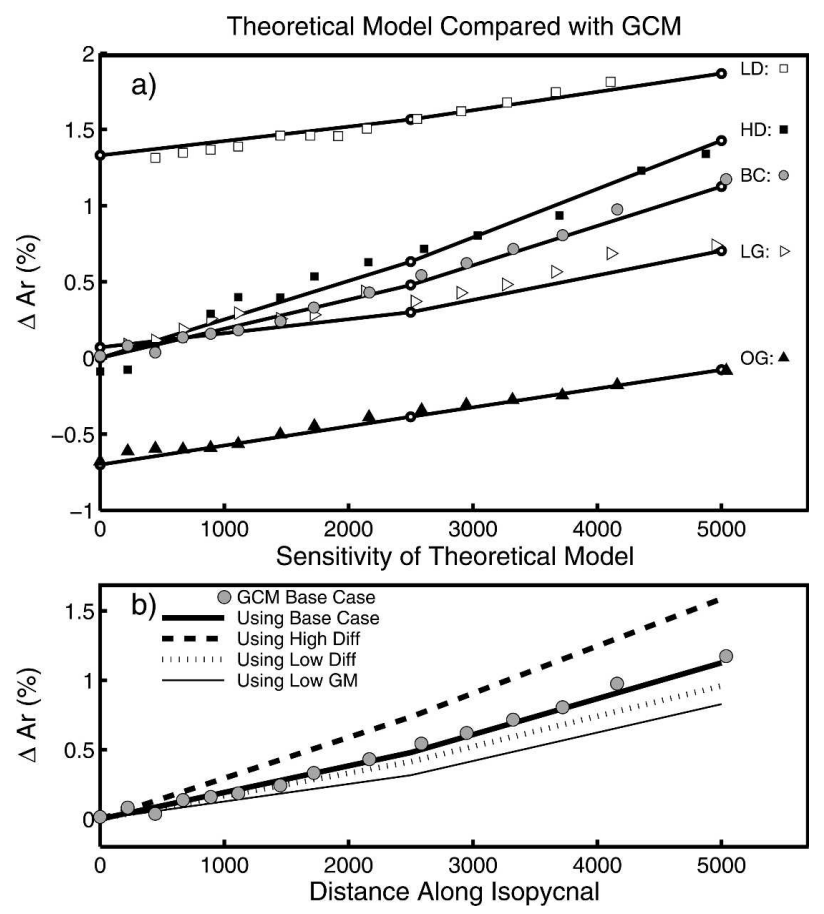

FIG. 9. (a) The results from the theoretical mixing model $\Delta \mathrm{Ar}$ in all the model cases (lines, with dots indicating box locations) as a function of surface temperature, compared with the results from the full GCM (symbols LD: Low Diff; HD: High Diff; BC: Base Case; LG: Low GM; OG: OCMIP Gas). The Low Diff case has been displaced upward by $1 \%$ in the interest of figure clarity. (b) The sensitivity of the theoretical model to the mixing parameters. The gray dots show the GCM $\triangle \mathrm{Ar}$ values in the Base Case, and the heavy solid line shows the theoretical model as in (a). The other lines show the theoretical model predictions using the $\Delta \mathrm{Ar}$ boundary values from the Base Case but the vertical and eddy diffusivities for the High Diff (dashed), Low Diff (dotted), and Low GM (light solid) cases. The OCMIP Gas case would appear as the same line as the Base Case since they have the same physical parameters. 
higher or lower vertical or eddy diffusivity and those of the theoretical model using the correct diffusivities.

This suggests that the model could be used to determine the gyre-scale vertical and eddy diffusivities, given measurements of $\Delta \mathrm{Ar}$ in all five box locations and at the surface and in the abyss. Figure 10 suggests a method of analysis. The theoretical model predicts values at Gyre 2 and Gyre 3 using inputs of vertical and eddy diffusivities. Even if the model is given the correct diffusivities, there can be error between the predicted Gyre 2 and Gyre 3 values and the actual values. Using Fig. $9 \mathrm{~b}$ as a guide, we consider that this error could be $0.02 \%$ for Gyre 2 and $0.05 \%$ for Gyre 3. Then, we can run the theoretical model for a wide range of vertical and eddy diffusivities, and plot lines that are within the above error from the GCM Gyre 2 (solid) and Gyre 3 (dashed) lines, considering the vertical and eddy diffusivities to be unknown. The overlapping area (gray) shows the predicted range of combined vertical and eddy diffusivities for both the Base and Low Diff cases, along with a $\times$ showing the true GCM value for each. In each case, the results are consistent with a wide range of eddy diffusivities; however, the Base Case and Low Diff case are clearly separated, suggesting it is possible to distinguish between predictions of low, interior mixing values and higher average values due to topography or sidewalls. If the vertical diffusivity can be further constrained using other methods, then the model gives an estimate of the eddy diffusivity that is consistent with the observed $\Delta \mathrm{Ar}$ gradient.

\section{Equatorial thermocline}

Anticipating future $\Delta \mathrm{Ar}$ measurements, we also discuss the modeled $\Delta \mathrm{Ar}$ in the Pacific equatorial region. To support the large upwelling of cold water to the surface in the equatorial region, the diathermal mixing must be of $O(1)$ importance. However, the observed pycnocline is relatively sharp, suggesting the vertical diffusivity at the equator may be lower than in the subtropical gyres (Canuto et al. 2004). The upper portion of Fig. 11 shows the $\Delta$ Ar profile averaged in the eastern equatorial Pacific $\left(2^{\circ} \mathrm{S}-2^{\circ} \mathrm{N}, 80^{\circ}-160^{\circ} \mathrm{W}\right)$ for the different cases. Also shown in the dark black line is the theoretical mixing that would occur by mixing only the mixed layer and abyssal end members. Most cases have a temperature-symmetric maximum indicating mixing throughout the water column, but the values all lie below the theoretical limit, suggesting horizontal as well as vertical processes are setting the supersaturation. Again, the maximum $\Delta \mathrm{Ar}$ values increase with increasing diffusivity.

The lower portion of Fig. 11 shows $\Delta \mathrm{Ar}$ along the

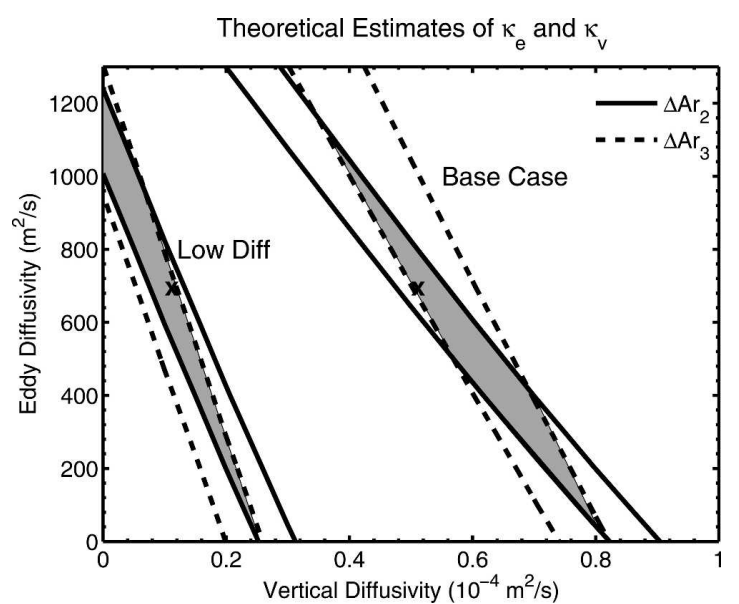

FIG. 10. An illustration of the way the theoretical model can be used as a tool to constrain the eddy and vertical diffusivities. We ran the theoretical model for a range of eddy diffusivities $(0-1300$ $\left.\mathrm{m}^{2} \mathrm{~s}^{-1}\right)$ and vertical diffusivities $\left(0-1 \times 10^{-4} \mathrm{~m}^{2} \mathrm{~s}^{-1}\right)$ using the boundary values for the Low Diff and Base Case. We then took the GCM values for $\triangle \mathrm{Ar}$ at the Gyre 2 and Gyre 3 locations in each case, considered the error could be $0.02 \%$ for Gyre 2 and $0.05 \%$ for Gyre 3, and plotted the theoretical model predictions that are within the error of the actual value observed (solid lines are Gyre $2 \Delta \mathrm{Ar} \pm 0.2 \%$ and dashed lines are Gyre $3 \Delta \mathrm{Ar} \pm$ $0.5 \%)$. The overlapping gray areas show the vertical and eddy diffusivities that are consistent with the observed Gyre 2 and Gyre 3 values, given the potential error specified. The $\times$ show the actual vertical and eddy diffusivities used in the GCM.

26.4- $\sigma$ surface $\left(\sim 12^{\circ} \mathrm{C}\right)$ as a function of longitude at the equator in the Pacific. Away from the eastern cold pool, the cases with varying diffusivities (Low Diff, Base Case, and High Diff) have nearly constant $\Delta$ Ar regardless of the longitude (or surface temperature) and the values increase with increasing vertical diffusivity. The Low GM case, however, shows an increase in $\Delta$ Ar from west to east, and the Low Diff case has higher values in the cold pool.

These observations lead to the conclusion that horizontal processes are responsible for reducing the gradient across much of the equatorial region. The westto-east zonal velocity is strong in the west but greatly diminishes across the strong temperature gradient in the cold pool in the east. This advection will have the largest influence on the Low Diff case, which has a longer diffusive time scale, and the $\Delta \mathrm{Ar}$ gradient increases in the cold pool as the velocity decreases. The equator also has lateral exchange via eddies with the subtropical thermocline, which further smoothes the gradient; the Low GM case, which lacks this influence, has a marked gradient from west to east.

\section{Summary and discussion}

The preceding analysis suggests that argon, as a noble gas with a nonlinear saturation curve and rela- 

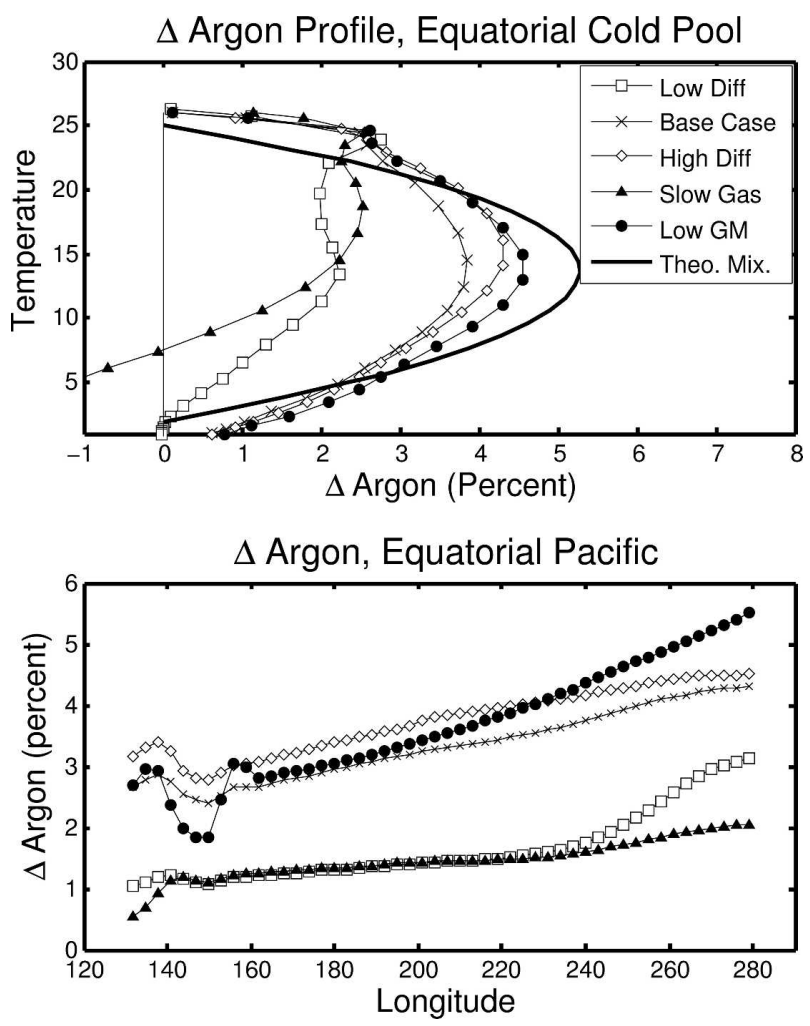

FIG. 11. (top) The $\Delta \mathrm{Ar}$ profiles for all the modeled cases in the east equator $\left(2^{\circ} \mathrm{S}-2^{\circ} \mathrm{N}, 80^{\circ}-160^{\circ} \mathrm{W}\right)$. Also shown in the solid line is the theoretical mixing curve if the surface and abyssal water masses were mixed equally. (bottom) The $\Delta$ Ar values along the 26.4- $\sigma$ surface $\left(\sim 12^{\circ} \mathrm{C}\right)$ as a function of longitude for all the cases along the equator in the Pacific. Warmer temperature surfaces are to the left (west) and colder surface temperatures are to the right (east).

tively small glacier and bubble effects, can be useful as a chemical tracer to trace diathermal mixing. Argon supersaturation magnitudes depend on both the local temperature (and, to a lesser extent, salinity) and on the temperature and argon of the water masses used to create the local water mass. Larger temperature differences between end members or colder local temperatures imply higher supersaturation values. We have found that the argon supersaturation traces the mixing history of a water mass rather than the local mixing, especially in regions where the advective time scale is shorter than the diffusive time scale. When the diffusive time scale is faster than the advective time scale, the supersaturation approaches the maximum value dictated by the surface and abyssal end members, and the along-isopycnal gradient is strong.

Based on the idea that local supersaturation depends on mixing from the mixed layer, abyss, western boundary current, and the upstream, upgradient, and downgradient water masses, we constructed a simple theo- retical model that can predict the gyre $\Delta \mathrm{Ar}$ gradient based on a knowledge of the isopycnal temperature; the surface temperatures and degree of supersaturation; the $\Delta \mathrm{Ar}$ in the poleward portion of the gyre, in the western boundary current and at the equator; and the relative advection, vertical diffusion, and eddy diffusion time scales. The agreement with the full general circulation model is good, suggesting this model can be used as a tool to give estimates of the vertical diffusivity $\kappa_{D}$ and the eddy diffusivity $\kappa_{e}$ on the gyre scale provided the depth scale is carefully set. These estimates will include the error implicit in the theoretical model and also errors introduced because the real ocean, unlike the model, is not in a statistically steady state. However, the results based on the general circulation model parameter study suggest the model is sensitive enough to distinguish between, for example, the low interior values reported in Ledwell et al. (1998) and the higher values over rough topography and within several hundred kilometers of the side boundaries, as reported in Polzin et al. (1997) and Naveira Garabato et al. (2004), respectively. The model may also be used to get an estimate of the relative contribution of the eddy and vertical diffusion on a gyrewide scale, helping to better constrain biogeochemistry ocean models.

Several argon datasets already exist. In the Atlantic subtropical thermocline, Hamme and Emerson (2002) measured the deviation from saturation at Bermuda and linked the mixed layer supersaturations to diffusive gas exchange, bubble injection, and solar heating. However, they did not collect samples in the depth range of the thermocline, so future datasets will be needed to verify the existence and nature of the subsurface supersaturation signal. In the equatorial Pacific, Bieri and Koide (1972) measured the deviation from saturation and found a thermocline supersaturation signal, but this older dataset is less precise than the Hamme and Emerson study, and the spread of the thermocline values is considerable. More recently, Gehrie et al. (2006) have confirmed a subsurface maxima in measured $\Delta \mathrm{Ar}$ in the equatorial Pacific, and their analysis shows this $\Delta \mathrm{Ar}$ is consistent with a GCM including mixing, heating, and bubble effects, although comparison in the abyss suggests the GCM has too much cumulative mixing along the lifetime of a deep water parcel.

Previous studies have used a combination of age and other tracers to constrain the along-isopycnal diffusivity and velocity in the thermocline (e.g., Jenkins 1998; Robbins et al. 2000). However, different age tracers, when susceptible to cumulative cross-isopycnal mixing, can give different measures of age, all of which can differ from the ideal age (Robbins and Jenkins 1998; 
Waugh et al. 2003). Argon can aid in the interpretation of age tracers, since regions with a large along-stream $\Delta$ Ar gradient suggest regions where the cumulative effect of mixing is strong and the ideal age will differ more strongly from the age derived from age tracers.

Acknowledgments. We thank John Chiang for insightful discussions while formulating the theoretical model and Scott Doney and one anonymous reviewer for their helpful comments. CCH and IF were supported by NSF ATM- 9987457.

\section{REFERENCES}

Archer, D. E., G. Eshel, A. Winguth, W. Broecker, R. Pierrehumbert, M. Tobis, and R. Jacob, 2000: Atmospheric $p \mathrm{CO} 2$ sensitivity to the biological pump in the ocean. Global Biogeochem. Cycles, 14, 1219-1230.

Bieri, R. H., and M. Koide, 1972: Dissolved noble gases in the east equatorial and southeast Pacific. J. Geophys. Res., 77, 16671676.

Canuto, V. M., A. Howard, Y. Cheng, and R. L. Miller, 2004: Latitude-dependent vertical mixing and the tropical thermocline in a global OGCM. Geophys. Res. Lett., 31, L16305, doi:10.1029/2004GL019891.

Gehrie, E., D. Archer, S. Emerson, C. Stump, and C. Henning, 2006: Subsurface ocean argon disequilibrium reveals the equatorial Pacific shadow zone. Geophys. Res. Lett., 33, 18608, doi:10.1029/2006GL026935.

Gent, P. R., J. Willebrand, T. McDougall, and J. C. McWilliams, 1995: Parameterizing eddy-induced tracer transports in ocean circulation. J. Phys. Oceanogr., 25, 463-474.

Gnanadesikan, A., R. D. Slater, N. Gruber, and J. L. Sarmiento, 2002: Oceanic vertical exchange and new production: A comparison between models and observations. Deep-Sea Res. II, 49, 363-401.

_ , J. P. Dunne, R. M. Key, K. Matsumoto, J. L. Sarmiento, R. D. Slater, and P. S. Swathi, 2004: Oceanic ventilation and biogeochemical cycling: Understanding the physical mechanisms that produce realistic distributions of tracers and productivity. Global Biogeochem. Cycles, 18, GB4010, doi:10.1029/2003GB002097.

Hamme, R. C., and S. R. Emerson, 2002: Mechanisms controlling the global oceanic distribution of the inert gases argon, nitrogen, and neon. Geophys. Res. Lett., 29, 2120, doi:10.1029/ 2002 GL015273.

Henning, C. C., and G. K. Vallis, 2004: The effects of mesoscale eddies on the main subtropical thermocline. J. Phys. Oceanogr., 34, 2428-2443.

Jenkins, W. J., 1998: Studying subtropical thermocline ventilation and circulation using tritium and ${ }_{3}$ He. J. Geophys. Res., 103, $15817-15831$.

Kelley, D. E., and K. A. Van Scoy, 1999: A basinwide estimate of vertical mixing in the upper pycnocline: Spreading of bomb tritium in the North Pacific Ocean. J. Phys. Oceanogr., 29, 1759-1771.
Large, W. G., G. Danabasoglu, S. C. Doney, and J. C. McWilliams, 1997: Sensitivity to surface forcing and boundary layer mixing in a global ocean model: Annual-mean climatology. $J$. Phys. Oceanogr., 27, 2418-2447.

Ledwell, J. R., and A. J. Watson, 1991: The Santa-Monica Basin Tracer Experiment-A study of diapycnal and isopycnal mixing. J. Geophys. Res., 96, 8695-8718.

$\longrightarrow,-$, and C. S. Law, 1998: Mixing of a tracer in the pycnocline. J. Geophys. Res., 103, 21 499-21 528.

Mignone, B. K., J. L. Sarmiento, R. D. Slater, and A. Gnanadesikan, 2004: Sensitivity of sequestration efficiency to mixing processes in the global ocean. Atmos. Energy, 29, 1467-1478.

Munk, W., and C. Wunsch, 1998: Abyssal recipes II: Energetics of tidal and wind mixing. Deep-Sea Res. I, 45, 1977-2010.

Naveira Garabato, A. C., K. I. C. Oliver, A. J. Waston, and M.-J. Messias, 2004: Turbulent diapycnal mixing in the Nordic seas. J. Geophys. Res., 109, C12010, doi:10.1029/2004JC002411.

Ohlmann, J. C., D. A. Siegel, and C. Gautier, 1996: Ocean mixed layer radiant heating and solar penetration: A global analysis. J. Climate, 9, 2265-2280.

Orr, J. C., and Coauthors, 2001: Estimates of anthropogenic carbon uptake from four three-dimensional global ocean models. Global Biogeochem. Cycles, 15, 43-60.

Polzin, K. L., J. M. Toole, J. R. Ledwell, and W. Schmitt, 1997: Spatial variability of turbulent mixing in the abyssal ocean. Science, 276, 93-96.

Radko, T., and J. Marshall, 2003: Equilibration of a warm pumped lens on a $\beta$ plane. J. Phys. Oceanogr., 33, 885-899.

— and - 2004: The leaky thermocline. J. Phys. Oceanogr., 34, 1648-1662.

Redi, M. H., 1982: Oceanic isopycnal mixing by coordinate rotation. J. Phys. Oceanogr., 12, 1154-1158.

Robbins, P. E., and W. J. Jenkins, 1998: Observations of temporal changes of tritium- ${ }_{3} \mathrm{He}$ age in the eastern North Atlantic thermocline: Evidence for changes in ventilation? J. Mar. Res., 56, 1125-1161.

— J. F. Price, W. Brechner Owens, and W. J. Jenkins, 2000: The importance of lateral diffusion for the ventilation of the lower thermocline in the subtropical North Atlantic. J. Phys. Oceanogr., 30, 67-89.

Ruddick, B., D. Walsh, and N. Oakey, 1997: Variations in apparent mixing efficiency in the North Atlantic Central Water. $J$. Phys. Oceanogr., 27, 2589-2605.

Samelson, R. M., and G. K. Vallis, 1997: Large-scale circulation with small diapycnal diffusion: The two-thermocline limit. $J$. Mar. Res., 55, 223-275.

Scott, J. R., and J. Marotzke, 2002: The location of diapycnal mixing and the meridional overturning circulation. J. Phys. Oceanogr., 32, 3578-3595.

Watson, A. J., and J. R. Ledwell, 2000: Oceanographic tracer release experiments using sulphur hexafluoride. J. Geophys. Res., 105, 14 325-14 337.

Waugh, D. W., T. M. Hall, and T. W. N. Haine, 2003: Relationships among tracer ages. J. Geophys. Res., 108, 3138, doi:10.1029/2002JC001325.

Well, R., and W. Roether, 2003: Neon distribution in South Atlantic and South Pacific waters. Deep-Sea Res. I, 50, 721735 . 